\title{
The effect of 'impure' pore fluids on metamorphic dissociation reactions.
}

\author{
By Peter J. Wyllie, B.Sc., Ph.D. \\ Dept. of Geology, University of Leeds. ${ }^{1}$
}

[Read 3 November 1960.]

\begin{abstract}
Summary. Comparison of experimental data from the systems $\mathrm{MgO}_{-} \mathrm{CO}_{2}-\mathrm{H}_{2} \mathrm{O}$ (closed) and $\mathrm{MgO}-\mathrm{CO}_{2}-\mathrm{A}$ (simulating an open system) shows that the effects of $\mathrm{H}_{2} \mathrm{O}$ and $\mathrm{A}$ on the dissociation of magnesite are almost identical; both behave as inert components reducing the partial pressure of $\mathrm{CO}_{2}$. The dissociation temperature at constant total pressure is lowered according to the proportion of inert volatiles in the initial vapour phase. The dissociation is completed at one temperature (univariant) in an open system but in a closed system it proceeds through a temperature interval (divariant) because the vapour phase changes composition. The amount of dissociation remains small until the upper limit of the interval is reached. More complex dissociation reactions in the systems CaO- $\mathrm{MgO}-\mathrm{CO}_{2}-\mathrm{H}_{2} \mathrm{O}$ and $\mathrm{CaO}-\mathrm{SiO}_{2}-\mathrm{CO}_{2}-\mathrm{H}_{2} \mathrm{O}$ are described; they follow similar patterns. Under closed or partially open metamorphic conditions non-reacting pore fluid components (inert) have to be treated as one additional component for application of the mineralogical phase rule. Comparison of the pattern of metamorphic parageneses with the patterns of reactions occurring under known experimental conditions may provide information about metamorphic processes. Metamorphic reactions can be represented within a petrogenetic model with axes $P, T$, and pore fluid composition varying between $\mathrm{H}_{2} \mathrm{O}$ and $\mathrm{CO}_{2}$.
\end{abstract}

$\mathrm{F}$

XPERIMENTAL data are now available for many simple de$\triangle$ carbonation and dehydration reactions. Most experiments have been carried out in closed systems containing only one volatile component; dehydration reactions were investigated in the presence of $\mathrm{H}_{2} \mathrm{O}$ and decarbonation reactions in the presence of $\mathrm{CO}_{2}$. Recently, however, Harker (1958) and Greenwood (1960) have investigated the effect of an inert gas on dissociation reactions in the systems $\mathrm{MgO}_{-} \mathrm{CO}_{2}-\mathrm{A}$ and $\mathrm{NaAlSi}_{2} \mathrm{O}_{6}-\mathrm{H}_{2} \mathrm{O}-\mathrm{A}$, and results from the system $\mathrm{MgO}-\mathrm{CO}_{2}-\mathrm{H}_{2} \mathrm{O}$ (Walter, Wyllie, and Tuttle, 1962) provide similar data for the dissociation of magnesite and of brucite in the presence of a vapour phase containing the two volatile components that are probably most abundant in the pore fluid of rocks undergoing metamorphism.

It is unlikely that metamorphic systems are ever completely closed to

1 Present address: College of Mineral Industries, The Pennsylvania State University, University Park, Pennsylvania, U.S.A. 
the pore fluid components, and experimental data are therefore required in open as well as in closed systems. For dissociation reactions occurring in the presence of a vapour phase containing two volatile components, experimental data obtained under closed conditions may be used to illustrate the nature of the reactions in an open system.

This paper is mainly concerned with the effect of non-reacting (inert) volatiles on dissociation reactions, using as examples the experimental data from the systems $\mathrm{MgO}-\mathrm{CO}_{2}-\mathrm{A}$ and $\mathrm{MgO}-\mathrm{CO}_{2}-\mathrm{H}_{2} \mathrm{O}$. An attempt is made to illustrate in graphical rather than thermodynamic terms the differences between open and closed systems. Application of the conclusions to metamorphism is briefly discussed.

\section{Closed and open systems.}

A closed system has a definite bulk composition that remains constant during reactions. Between an open system and its surroundings exchange of material may occur, often in such a way that the chemical potentials of certain components are maintained at a constant level within the system by external conditions, whatever the reactions occurring. Any of these 'perfectly mobile' components may therefore move into or out of the system under controlled conditions (Korzhinskiir, 1936, 1959; Thompson, 1955). When open conditions are considered in this paper, only the volatile or gaseous components of the experimental systems are treated as perfectly mobile components.

The differences between closed and open systems are usually expressed rigorously in thermodynamic terms, but by means of phase diagrams they can be graphically illustrated for simple systems, in a qualitative way, if the chemical potential of a volatile component can be related to its concentration in the vapour phase. The chemical potential of a component may usually be written as a function of pressure, temperature, and concentration: it always increases with increasing concentration, it may increase or decrease with increasing pressure or temperature: and it may increase, decrease, or be unaffected by a change in concentration of some other component.

If the composition of a vapour phase is fixed at constant pressure and temperature, the concentrations of the components and thus their chemical potentials are also fixed. For the purpose of qualitative illustration we shall assume that moderate temperature changes at constant pressure do not affect the chemical potentials of the vapour phase components. If the vapour phase composition remains constant during a reaction, we have then an approximation to the condition that the 
chemical potentials of the volatile components also remain constant. This corresponds to an open system where the chemical potentials of the perfectly mobile components are fixed by conditions external to the system. In closed systems, on the other hand, volatiles released during dissociation reactions may cause the vapour phase to change composition with a corresponding change in the chemical potentials of the vapour phase components.

Experimental studies involving two volatile components.

Experimental data on systems containing more than one volatile component are still scarce, but techniques developed recently make possible the study of a wide range of such systems.

There are two general approaches. In the first, the volatiles are pumped into a pressure vessel, coming directly into contact with the crystalline components wrapped in platinum or gold foil. Although the system is closed, it contains a practically unlimited excess of vapour. The vapour composition thus remains effectively constant whatever the reactions occurring between the vapour phase and crystalline components, and the approach therefore approximates conditions in an open system, with vapour phase components (the volatiles) corresponding to perfectly mobile components. In the second approach, the crystalline and volatile components are sealed together within small gold or platinum capsules, the walls of which bound a closed system. There may be either an excess or a deficiency of volatiles, but even with an excess the amount available is not unlimited. The vapour phase may therefore change in composition and in amount during a dissociation reaction.

The first approach has been used by Yoder $(1954$, p. 121) in the system $\mathrm{NaAlSi}_{2} \mathrm{O}_{6}-\mathrm{H}_{2} \mathrm{O}-\mathrm{A}$, by Harker (1958) in the system $\mathrm{MgO}_{-} \mathrm{CO}_{2}-\mathrm{A}$, and by Wyllie and Tuttle (1959) in the systems albite- $\mathrm{H}_{2} \mathrm{O}-\mathrm{CO}_{2}$ and granite $-\mathrm{H}_{2} \mathrm{O}-\mathrm{CO}_{2}$. Experimental difficulties were successfully resolved by Harker, who obtained a homogeneous vapour phase containing two volatiles by mixing the gases in a pump prior to their injection into the pressure vessel. The approach is effective but limited in scope. It would be difficult to mix $\mathrm{H}_{2} \mathrm{O}$ and $\mathrm{CO}_{2}$ in a pump, except for a limited range of composition, and it is unsuitable for corrosive materials. Greenwood (1960) has published the results of successful experiments in the system $\mathrm{NaAlSi}_{2} \mathrm{O}_{6}-\mathrm{H}_{2} \mathrm{O}-\mathrm{A}$, but no experimental details were included in the abstract available at the time of writing.

The second approach, using small sealed capsules, provides two methods for studying the effects of mixed volatiles on high pressure 
reactions. In one method a stable hydrous solution of a second volatile is weighed into a capsule together with solid components (Wyllie and Tuttle, 1961). In the other method $\mathrm{H}_{2} \mathrm{O}$ and crystalline materials containing carbonate are sealed within a capsule. Under appropriate experimental conditions $\mathrm{CO}_{2}$ is released from the crystalline components and mixes with the $\mathrm{H}_{2} \mathrm{O}$ vapour (Wyllie and Tuttle, 1960; Walter, Wyllie, and Tuttle, 1962). The composition of the vapour phase for any bulk composition at any pressure and temperature can be determined graphically from the phase relationships.

All these experimental methods yield data only for the condition where the pressure on the vapour phase equals the pressure on the crystalline phases.

$$
\mathrm{MgO}-\mathrm{CO}_{2}-\mathrm{A} \text {. }
$$

Harker (1958) studied the dissociation of magnesite in the presence of gases containing various proportions of $\mathrm{CO}_{2}$ and $\mathrm{A}$. The quantity of crystalline material was kept to an absolute minimum and enough gas was present to ensure that its composition did not change appreciably during dissociation. He thus achieved experimentally the conditions corresponding to an open system with perfectly mobile components $\mathrm{CO}_{2}$ and $\mathrm{A}$. The system was represented by the charge of magnesite with the vapour phase in contact with it, and the external conditions were represented by the large excess of vapour of fixed composition imparting pressure to the system. Results were presented as a series of univariant $P T$ curves, each representing the reaction in the presence of a gas containing a fixed ratio of $\mathrm{CO}_{2}: \mathrm{A}$ (compare fig. $3 \mathrm{~A}$ ). Dilution of $\mathrm{CO}_{2}$ with $\mathrm{A}$ at constant total pressure reduced the partial pressure of $\mathrm{CO}_{2}$ and the dissociation therefore proceeded at a lower temperature.

Harker's data can be transferred to ternary diagrams and from these the pattern of dissociation of magnesite in the closed system $\mathrm{MgO}_{-} \mathrm{CO}_{2}-\mathrm{A}$ can be ascertained. Harker's fig. 5 shows that at 1000 bars total pressure gases with $\mathrm{CO}_{2}: \mathrm{A}$ ratios of $9: 1,4: 1,2: 1,1: 1$, and $1: 2$ coexist with magnesite and periclase at $770^{\circ} \mathrm{C}, 760^{\circ} \mathrm{C}, 740^{\circ} \mathrm{C}, 715^{\circ} \mathrm{C}$, and $680^{\circ} \mathrm{C}$ respectively. A three-phase triangle for each of these temperatures is obtained by joining the appropriate vapour composition to $\mathrm{MgO}$ and $\mathrm{MgCO}_{3}$. Fig. $1 \mathrm{~A}$ is a composite diagram showing three triangles. For a vapour phase consisting of pure $\mathrm{CO}_{2}$ the triangle becomes a line at $780^{\circ} \mathrm{C}$.

From fig. $1 \mathrm{~A}$ the phase spaces intersected by the join $\mathrm{MgCO}_{3} \mathrm{~A}$ can be constructed and the results are shown in fig. 1 B. Space limitations 
do not permit a description but the method of construction should be evident from comparison of figs. $1 \mathrm{~A}$ and $1 \mathrm{~B}$. By reversing the procedure a three-phase triangle for any temperature can be constructed from fig. $1 \mathrm{~B}$ and the vapour phase composition for the selected temperature can be obtained from fig. $1 \mathrm{~A}$. Diagrams similar to fig. 1 в can be constructed for any join connecting $\mathrm{MgCO}_{3}$ to a given vapour composition. Fig. 1 thus provides a complete picture of the sub-solidus phase relations in the $T X$ prism for 1000 bars pressure. A similar prism can be obtained for any pressure in the range studied by Harker.
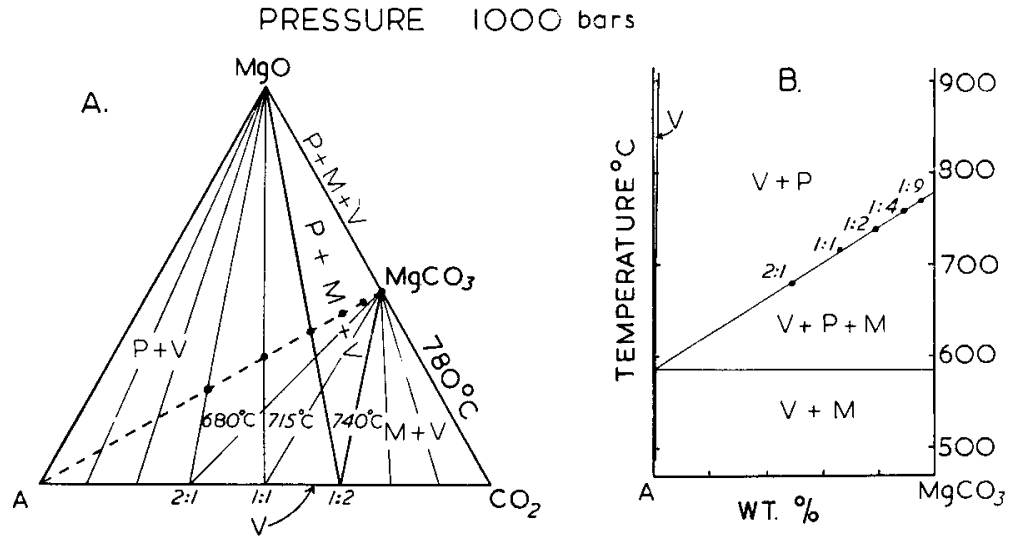

Fig. 1. $M$, magnesite; $P$, periclase; $V$, vapour. A, composite diagram showing four isothermal sections through the $T X$ prism for the system $\mathrm{MgO}_{-} \mathrm{CO}_{2}-\mathrm{A}$ at 1000 bars pressure. The positions of the three-phase triangles were constructed from Harker's (1958) data. $\mathrm{B}$, isobaric diagram for the join $\mathrm{MgCO}_{3}-\mathrm{A}$ constructed from fig. $1 \mathrm{~A}$. This is a vertical section through the $T X$ prism (periclase and vapour compositions cannot be represented on this join). The ratios $2: 1$, etc., give the compositions of the vapours at the plotted points in terms of $\mathrm{A}: \mathrm{CO}_{2}$.

The pattern of dissociation for any bulk composition in the closed system $\mathrm{MgO}-\mathrm{CO}_{2}-\mathrm{A}$ is given in a $T X$ prism. For example, any mixture of $\mathrm{MgCO}_{3}$ and $\mathrm{A}$ at 1000 bars pressure begins to dissociate at $585^{\circ} \mathrm{C}$ (fig. $1 \mathrm{~B}$ ), it continues through a dissociation interval as $\mathrm{CO}_{2}$ is released to the vapour phase at constant total pressure, and dissociation is completed at a temperature depending on the initial proportion of vapour in the mixture.

The experimental conditions simulating an open system are represented in fig. $1 \mathrm{~A}$ by bulk compositions lying almost at the vapour field. These compositions intersect very narrow parts of the three-phase triangles. A slight increase of temperature is therefore sufficient for passage from 
the field of $\mathrm{MgCO}_{3}+V$ to that of $\mathrm{MgO}+V$ and the dissociation occurs effectively at one temperature.

$$
\mathrm{MgO}-\mathrm{CO}_{2}-\mathrm{H}_{2} \mathrm{O} \text {. }
$$

Experimental results obtained in small sealed capsules (closed conditions) have provided a $T X$ prism for this system at 1000 bars pressure (Walter, Wyllie, and Tuttle, 1962). The spaces $\mathrm{MgCO}_{3}+V, \mathrm{MgCO}_{3}+$ $\mathrm{MgO}+V$, and $\mathrm{MgO}+V$ are almost identical with those in the prism for the system $\mathrm{MgO}-\mathrm{CO}_{2}-\mathrm{A}$. Small differences occur in the temperature scale; these are to be expected from the different properties of $\mathrm{H}_{2} \mathrm{O}$ and $\mathrm{A}$. A more significant difference between the two systems is that reaction. occurs between $\mathrm{H}_{2} \mathrm{O}$ and magnesite below $635^{\circ} \mathrm{C}$ when the vapour phase contains more than 94 weight per cent $\mathrm{H}_{2} \mathrm{O}$; a small amount of brucite is then developed. However, any join connecting $\mathrm{MgCO}_{3}$ to a vapour composition between $\mathrm{CO}_{2}$ and $94 \mathrm{H}_{2} \mathrm{O} \mathrm{CO}_{2}$ (weight per cent) has the same form as fig. $1 \mathrm{~B}$ and the phase spaces containing brucite can be ignored in the present discussion.

The pattern of dissociation of magnesite under either open or closed conditions in the presence of vapours containing $\mathrm{CO}_{2}$ and $\mathrm{H}_{2} \mathrm{O}$ can be ascertained by the methods outlined in the preceding section. The two different experimental approaches used for the study of the systems $\mathrm{MgO}-\mathrm{CO}_{2}-\mathrm{A}$ and $\mathrm{MgO}-\mathrm{CO}_{2}-\mathrm{H}_{2} \mathrm{O}$ thus provide essentially the same information for both open and closed conditions.

$$
\mathrm{MgO}-\mathrm{CO}_{2}-\mathrm{H}_{2} \mathrm{O}-\mathrm{A} \text {. }
$$

The experimental data indicate that $\mathrm{A}$ and $\mathrm{H}_{2} \mathrm{O}$ both behave as chemically inert components diluting the $\mathrm{CO}_{2}$ in the vapour phase. When magnesite dissociates in the system $\mathrm{MgO}-\mathrm{CO}_{2}-\mathrm{H}_{2} \mathrm{O}-\mathrm{A}$ any mixture of $\mathrm{H}_{2} \mathrm{O}$ and $\mathrm{A}$ behaves as a single inert component. This is illustrated by the isobaric isothermal tetrahedron in fig. 2. During the dissociation of magnesite in the presence of vapours on the line $X-\mathrm{CO}_{2}$ the vapour composition ( $V$ ) remains on $X-\mathrm{CO}_{2}$ and the join $\mathrm{MgO}_{-} \mathrm{CO}_{2}-X$ is therefore a ternary system. $X$, any mixture of $\mathrm{H}_{2} \mathrm{O}$ and $A$, thus behaves as a single component (except for high concentrations of $\mathrm{H}_{2} \mathrm{O}$ when brucite is formed).

\section{Effect of inert volatiles on the dissociation of magnesite.}

The dissociation of magnesite in the system $\mathrm{MgO}-\mathrm{CO}_{2}$ is represented by a univariant curve on a $P T$ projection (the right-hand curve in fig. $3 \mathrm{~A}$ ). For the experimental condition that the pressure on the vapour 
equals the pressure on the crystalline phases, the same curve applies to both open and closed systems. Addition of an inert volatile or a mixture of inert volatiles at constant total pressure causes the dissociation to proceed at a lower temperature. In an open system with all volatiles

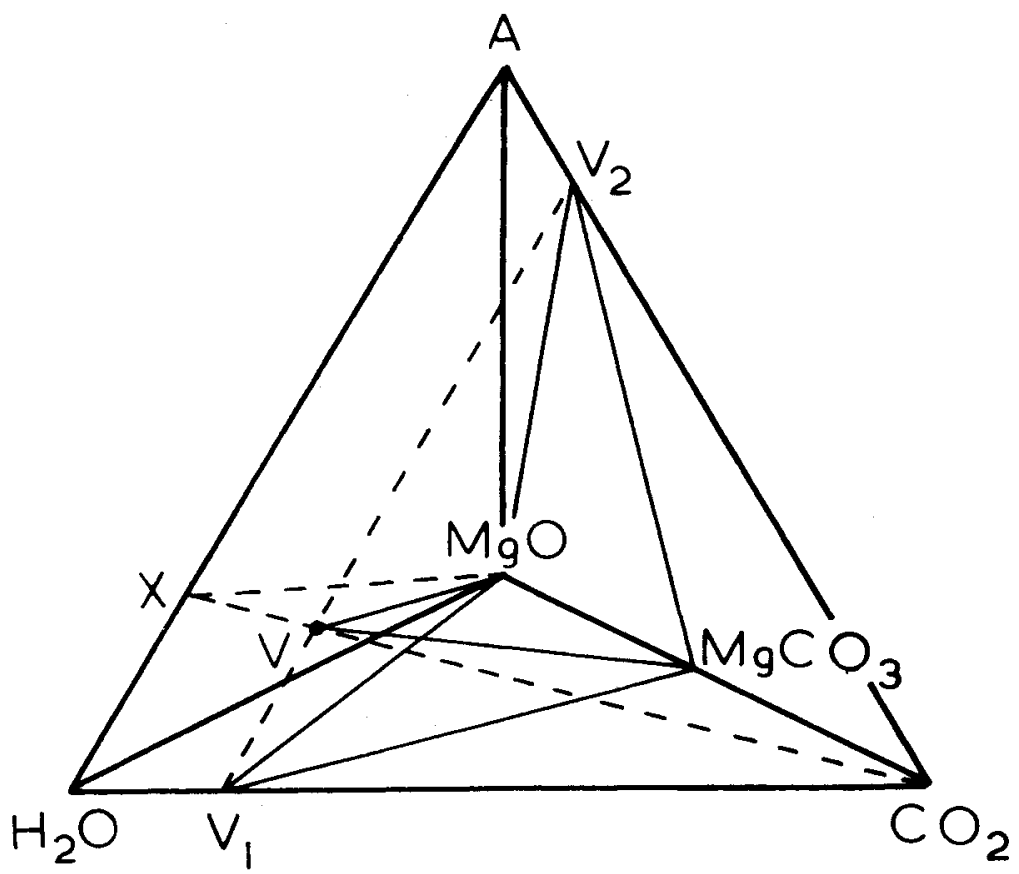

Fic. 2. Schematic isobaric isothermal tetrahedron for the system $\mathrm{MgO}-\mathrm{CO}_{2}-\mathrm{H}_{2} \mathrm{O}-\mathrm{A}$ at approximately 1000 bars and $650^{\circ} \mathrm{C}$. The line $V_{1} V_{2}$ gives the compositions of vapours that coexist with periclase and magnesite. The dissociation of magnesite in the presence of a vapour phase composed of $\mathrm{CO}_{2}+\mathrm{H}_{2} \mathrm{O}+\mathrm{A}$ is represented by a three-phase triangle such as $\mathrm{MgCO}_{3}-\mathrm{MgO}-V$. As the reaction proceeds with increasing temperature, $V$ changes towards $\mathrm{CO}_{2}$ along the line $\mathrm{X}-\mathrm{CO}_{2}$.

perfectly mobile, this is the only effect, but in a closed system the inert volatile (or volatile mixture) is a component despite the fact that it does not enter into the crystalline phases because its presence causes the vapour phase to change composition during the reaction. The dissociation therefore proceeds through a temperature interval.

$\mathrm{H}_{2} \mathrm{O}$ and $\mathrm{CO}_{2}$ are probably the most abundant and important constituents of the pore fluid in natural metamorphic systems and we shall therefore consider the dissociation of magnesite in their presence. However, $A$ and other inert components could be substituted for all or part 
of the $\mathrm{H}_{2} \mathrm{O}$ without changing conditions appreciably. The following illustrations for a vapour phase containing $\mathrm{H}_{2} \mathrm{O}$ and $\mathrm{CO}_{2}$ are based on Harker's data for the system $\mathrm{MgO}-\mathrm{CO}_{2}-\mathrm{A}$ because these are more complete than data for $\mathrm{MgO}-\mathrm{CO}_{2}-\mathrm{H}_{2} \mathrm{O}$.

Open system. Consider the dissociation of magnesite at constant pressure in the presence of $\mathrm{CO}_{2}$ and $\mathrm{H}_{2} \mathrm{O}$ with both volatiles perfectly mobile. For each constant vapour phase composition there is a different univariant curve for the dissociation. These occur at lower temperatures as the ratio of $\mathrm{CO}_{2}: \mathrm{H}_{2} \mathrm{O}$ in the vapour-phase is decreased (fig. $3 \mathrm{~A}$ ). Although the approximation that constant vapour-phase composition corresponds to constant chemical potentials of the vapour-phase components may hold through a very restricted range of $P$ and $T$, it is not valid for the $P T$ range covered by fig. $3 \mathrm{~A}$. The chemical potentials of the vapour phase components thus vary along each curve.

Closed system. In the closed system $\mathrm{MgO}-\mathrm{CO}_{2}-\mathrm{H}_{2} \mathrm{O}$ the dissociation is represented in $P T$ projection by a divariant band whose width depends upon the initial vapour phase composition and the initial ratio of magnesite:vapour. This is apparent from fig. 1. The examples illustrated in figs. $3 \mathrm{~B}, \mathrm{c}$, and $\mathrm{D}$ are for charges initially containing 5 weight per cent vapour with compositions $\mathrm{CO}_{2}: \mathrm{H}_{2} \mathrm{O}=2: 1,1: 2$, and pure $\mathrm{H}_{2} \mathrm{O}$.

When the initial vapour phase consists of pure $\mathrm{H}_{2} \mathrm{O}$ the boundaries of the band for any charge at 1000 bars pressure can be read directly from fig. 1 в. A similar diagram for 2000 bars pressure was constructed from Harker's data and additional points on the boundaries of the band in fig. $3 \mathrm{D}$ were obtained from this.

For vapours initially containing both $\mathrm{CO}_{2}$ and $\mathrm{H}_{2} \mathrm{O}$ the boundaries of the band for a fixed bulk composition at constant pressure are obtained from the temperatures of two three-phase triangles. Dissociation begins when the $\mathrm{MgCO}_{3}-\mathrm{V}$ side of a triangle reaches the bulk composition of the charge and it is completed when the $\mathrm{MgO}-\mathrm{V}$ side of a triangle reaches the same composition. The temperatures of the appropriate three-phase triangles for any bulk composition can be obtained from the $T X$ prism using the constructions mentioned previously.

The curves that mark the beginning of the dissociation interval in figs. $3 \mathrm{~B}, \mathrm{C}$, and $\mathrm{D}$ are fixed by the initial vapour composition regardless of its amount. These are the curves for complete reaction in open systems with the same vapour-phase composition (fig. $3 \mathrm{~A}$ ). The positions of the curves that mark the completion of dissociation depend mainly on the initial proportion of magnesite: vapour, and for small vapour concentrations they lie only slightly to the left of that for the system $\mathrm{MgO}-\mathrm{CO}_{2}$. 


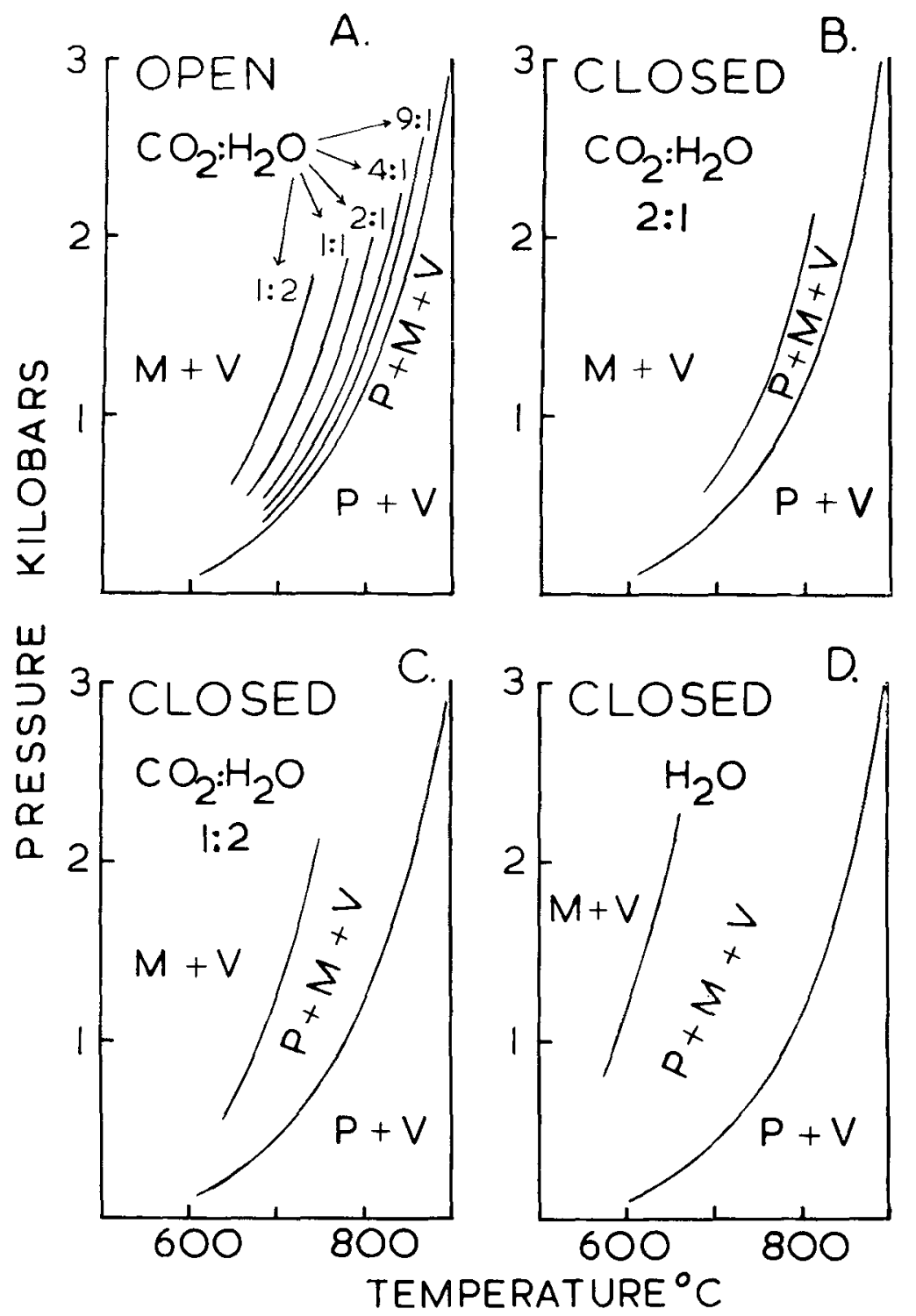

FIG. 3. $M$, magnesite; $P$, periclase; $V$, vapour. The system $\mathrm{MgO}-\mathrm{CO}_{2}-\mathrm{H}_{2} \mathrm{O}$. $A$, univariant dissociation curves for magnesite in the presence of vapours of fixed composition (from Harker's data) in open systems. The right-hand curve is for dissociation in the presence of $\mathrm{CO}_{2}$ (system $\mathrm{MgO}_{-} \mathrm{CO}_{2}$ ). $\mathrm{B}, \mathrm{C}$, and D. Divariant dissociation intervals for magnesite in closed systems with various initial vapour phase compositions. The curves for the beginning of dissociation correspond to the equivalent curves in fig. $3 \mathrm{~A}$, becoming lower with increase in $\mathrm{H}_{2} \mathrm{O}$ content of the vapour. These are independent of the proportion of vapour initially present. The right-hand curves, for an initial vapour content of 5 weight per cent, are only a few degrees to the left of the right-hand curve in fig. $3 \mathrm{~A}$. 
In figs. $3 \mathrm{~B}, \mathrm{C}$, and $\mathrm{D}$ the right-hand curve is less than $5^{\circ} \mathrm{C}$ below the binary curve. The effect on the right-hand curve of the initial ratio of $\mathrm{CO}_{2}: \mathrm{H}_{2} \mathrm{O}$ in the vapour is very small except for charges containing high proportions of vapour.

The dissociation interval in closed systems. During the dissociation interval at constant pressure the proportions of the three phases at any temperature can be measured from the position of the bulk composition within the appropriate three-phase triangle. The stage reached by the reaction is indicated by the percentage of periclase present in the crystalline phases, as shown in fig. 4 for charges containing magnesite and various proportions of $\mathrm{H}_{2} \mathrm{O}$.

With an initial vapour phase of pure $\mathrm{H}_{2} \mathrm{O}$ all charges begin to dissociate at $585^{\circ} \mathrm{C}$ at 1000 bars pressure. (The trace of brucite occurring below $585^{\circ} \mathrm{C}$ is ignored.) Increase in temperature at first produces only a small amount of dissociation and not until the upper part of the interval is reached does much further dissociation occur. For example, although the charge containing $1 \% \mathrm{H}_{2} \mathrm{O}$ begins to dissociate at $585^{\circ} \mathrm{C}$ only $2 \%$ periclase is present in the crystalline phases at $740^{\circ} \mathrm{C}$. At about $778^{\circ} \mathrm{C}$ the dissociation is completed and the charge then contains $100 \%$ periclase. The temperature of complete dissociation at constant pressure is lowered by increase in the initial vapour: magnesite ratio but the magnitude of this effect is quite small compared to the width of the dissociation interval.

For each initial vapour phase composition between pure $\mathrm{H}_{2} \mathrm{O}$ and pure $\mathrm{CO}_{2}$ there is a similar family of curves leaving the base line at some temperature between $585^{\circ} \mathrm{C}$ and $780^{\circ} \mathrm{C}$. For pure $\mathrm{CO}_{2}$ the family of curves degenerates to a vertical line at $780^{\circ} \mathrm{C}$ as illustrated.

At fixed pressure and temperature within the dissociation interval the percentage of periclase developed is less for charges initially containing vapours with higher $\mathrm{CO}_{2}: \mathrm{H}_{2} \mathrm{O}$ ratios. For example, consider a series of charges containing initially 10 weight per cent of vapour. At $760^{\circ} \mathrm{C}$ and 1000 bars pressure charges with initial vapour phase compositions $\mathrm{H}_{2} \mathrm{O}$, $\mathrm{H}_{2} \mathrm{O}: \mathrm{CO}_{2}=2: 1,1: 1,1: 2$ and $1: 4$ contain, respectively, $100 \%, 41 \%$, $21 \%, 11 \%$, and $0 \%$ of periclase in the crystalline phases.

\section{Effect of inert volatiles on decarbonation and dehydration reactions.}

The effect of inert volatiles on multicomponent decarbonation reactions in open and closed systems is very similar to their effect on the dissociation of magnesite. This is illustrated below for two quaternary systems. 


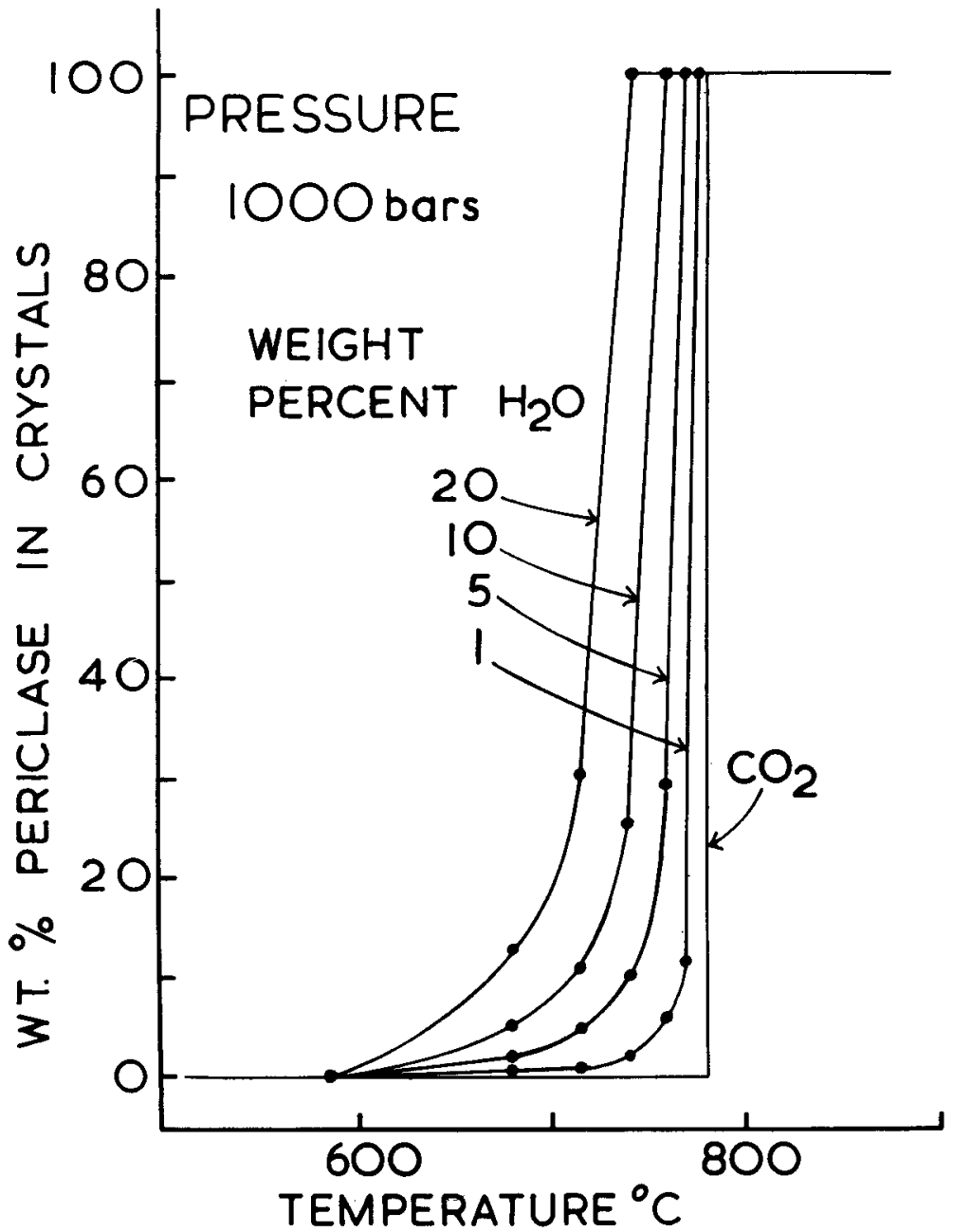

Fia. 4. The pattern of dissociation of magnesite in a closed system $\mathrm{MgO}-\mathrm{CO}_{2}-\mathrm{H}_{2} \mathrm{O}$ at 1000 bars pressure. The ordinate represents the stage reached by the dissociation. For all charges containing initially pure $\mathrm{H}_{2} \mathrm{O}$ vapour dissociation begins at $585^{\circ} \mathrm{C}$. For charges initially containing a different vapour dissociation would begin at a higher temperature (see figs. $3 \mathrm{~B}$, $\mathrm{C}$, and $\mathrm{D}$ ). The vertical line at $780^{\circ} \mathrm{C}$ represents the reaction for a vapour phase of pure $\mathrm{CO}_{2}$. At any temperature within the dissociation interval the extent of dissociation increases with increase in the initial percentage of vapour phase. Curves for initial contents of $1,5,10$, and 20 weight per cent of vapour have been drawn through the points plotted. 
$\mathrm{CaO}-\mathrm{MgO}-\mathrm{CO}_{2}-\mathrm{H}_{2} \mathrm{O}$. There are three univariant decarbonation reactions in the system $\mathrm{CaO}-\mathrm{MgO}-\mathrm{CO}_{2}$; the dissociations of magnesite, dolomite, and calcite. These have been investigated experimentally in the presence of $\mathrm{CO}_{2}$ (Smyth and Adams, 1923; Graf and Goldsmith, 1955; Harker and Tuttle, 1955). The reactions occurring at successively higher temperatures at constant pressure are: $\mathrm{MgCO}_{3} \rightleftharpoons \mathrm{MgO}+\mathrm{CO}_{2}$, $\mathrm{CaMg}\left(\mathrm{CO}_{3}\right)_{2} \rightleftharpoons \mathrm{CaCO}_{3}+\mathrm{MgO}+\mathrm{CO}_{2}$, and $\mathrm{CaCO}_{3} \rightleftharpoons \mathrm{CaO}+\mathrm{CO}_{2}$. Dolomite can coexist with the phases in the first reaction, and periclase with the phases in the third reaction. Each dissociation is thus represented by the coexistence of four phases: magnesite + periclase + dolomite + vapour, dolomite +calcite + periclase + vapour, and calcite + lime-periclase + vapour. The three crystalline phases in each reaction form a triangle on the $\mathrm{CaO}-\mathrm{MgO}-\mathrm{CO}_{2}$ face of the tetrahedron in fig. 5. One carbonate mineral and one triangle disappear at each isobaric reaction temperature until finally only periclase + lime - va pour remain. More detailed accounts of the reactions have been given by Bowen (1940) and Harker and Tuttle (1955). Solid solution between the minerals is omitted in fig. 5 .

When the reactions proceed in the presence of a vapour phase containing both $\mathrm{H}_{2} \mathrm{O}$ and $\mathrm{CO}_{2}$ the phase relationships can be illustrated within isobaric isothermal tetrahedra $\mathrm{CaO}-\mathrm{MgO}-\mathrm{CO}_{2}-\mathrm{H}_{2} \mathrm{O}$. Each dissociation is represented by a four-phase tetrahedron connecting the compositions of the coexisting phases, one side of each tetrahedron being formed by the triangles on the face $\mathrm{CaO}-\mathrm{MgO}-\mathrm{CO}_{2}$. Four-phase tetrahedra for the dissociation of magnesite and of dolomite, respectively, are shown by the dashed lines for magnesite + periclase + dolomite + vapour $\left(V_{1}\right)$ and by the dotted lines for dolomite + periclase + calcite + vapour $\left(V_{2}\right)$. The vapour compositions $V_{1}$ and $V_{2}$ on the join $\mathrm{H}_{2} \mathrm{O}-\mathrm{CO}_{2}$ actually lie on a vaporus surface very close to the join.

In a closed system liberation of $\mathrm{CO}_{2}$ during each reaction causes the vapours $V_{1}$ and $V_{2}$ to change composition, and with increasing temperature the four-phase tetrahedra move through the tetrahedron $\mathrm{CaO}-\mathrm{MgO}-$ $\mathrm{CO}_{2}-\mathrm{H}_{2} \mathrm{O}$. When $V_{1}=\mathrm{CO}_{2}$ the first tetrahedron degenerates to a triangle dolomite-periclase-(magnesite)- $\mathrm{CO}_{2}$. At a higher temperature when $V_{2}=\mathrm{CO}_{2}$ the second tetrahedron similarly degenerates to the quadrilateral dolomite-periclase-calcite- $\mathrm{CO}_{2}$. At much higher temperatures a third four-phase tetrahedron for calcite + lime + periclase + vapour $(V)$ appears in the system and with increasing temperature $V$ changes composition along the join $\mathrm{H}_{2} \mathrm{O}-\mathrm{CO}_{2}$. Except at very low pressures the situation is more complex than this because a melt appears near the join $\mathrm{Ca}(\mathrm{OH})_{2}-\mathrm{CaCO}_{3}$ at temperatures of the same order as those 
for the dissociation of magnesite and dolomite in the system $\mathrm{CaO}-\mathrm{MgO}$ $\mathrm{CO}_{2}$ (Wyllie and Tuttle, 1960). Several four-phase tetrahedra involving a liquid then appear in the left-hand part of fig. 5 before the two tetrahedra illustrated have reached the side $\mathrm{CaO}-\mathrm{MgO}-\mathrm{CO}_{2}$. Four-phase

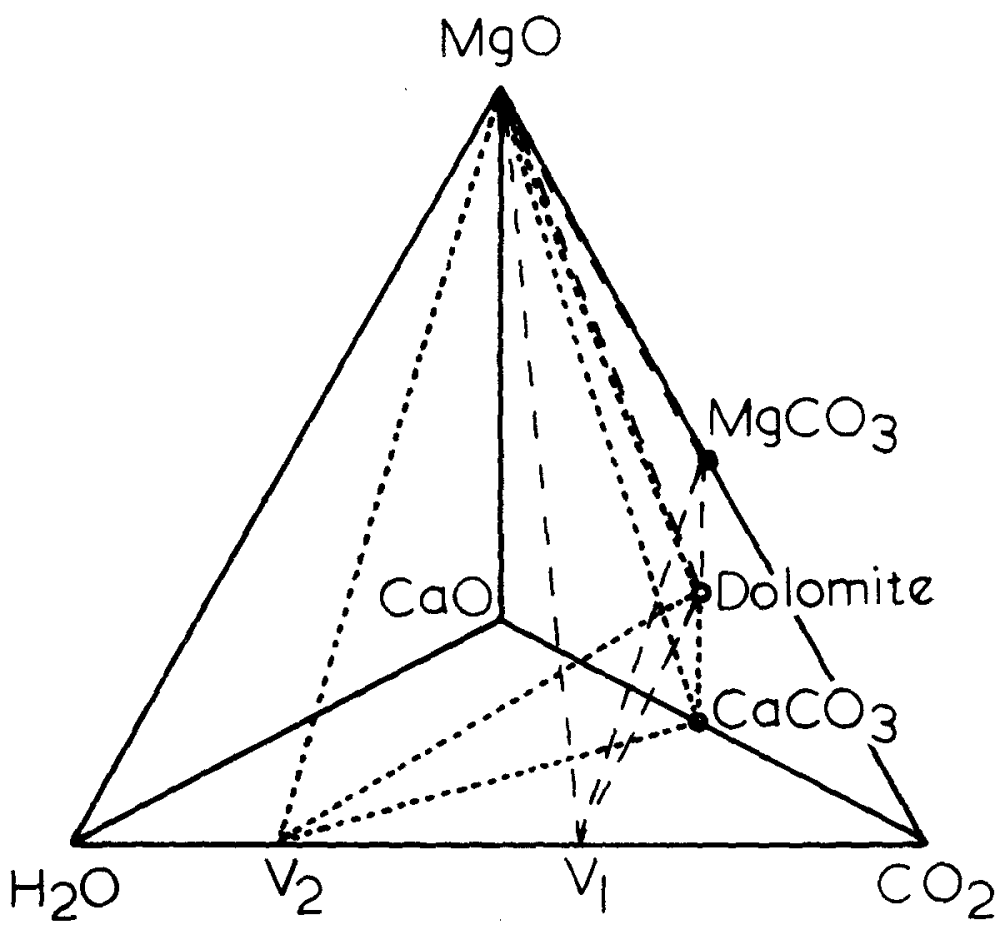

FIG. 5. Sehematic isobaric isothermal tetrahedron for the system $\mathrm{CaO}-\mathrm{MgO}-\mathrm{CO}_{2}-$ $\mathrm{H}_{2} \mathrm{O}$. The dissociation of dolomite is represented by the four-phase tetrahedron dolomite- $\mathrm{CaCO}_{3}-\mathrm{MgO}-V_{2}$ (dotted), and the dissociation of magnesite is represented by the four-phase tetrahedron $\mathrm{MgCO}_{3}-\mathrm{MgO}$-dolomite- $V_{1}$ (dashed). As the reactions proceed with increasing temperature the four-phase tetrahedra move through the quaternary tetrahedron as $V_{1}$ and $V_{2}$ change towards $\mathrm{CO}_{2}$.

tetrahedra near the face $\mathrm{CaO}-\mathrm{MgO}-\mathrm{H}_{2} \mathrm{O}$, involving the phases brucite and portlandite, need not be considered.

Movement of the four-phase tetrahedra through the quaternary tetrahedron is analogous to movement of the three-phase triangle periclase + magnesite + vapour through the ternary systems $\mathrm{MgO}_{-} \mathrm{CO}_{2}-$ $\mathrm{H}_{2} \mathrm{O}$ and $\mathrm{MgO}-\mathrm{CO}_{2}-\mathrm{A}$ (fig. $1 \mathrm{~A}$ ). Direct comparison is possible because the system $\mathrm{MgO}-\mathrm{CO}_{2}-\mathrm{H}_{2} \mathrm{O}$ forms one face of the quaternary tetrahedron. 
Coexistence of dolomite with the three phases transforms the triangle into a tetrahedron but this does not affect the changing composition of $V_{1}$ which controls movement of the triangle and of the tetrahedron.

Location of these four-phase spaces using either experimental approach would provide all the information required to trace the dissociation reactions for any bulk composition within the closed system, and to give the reaction temperature in the presence of a vapour phase of fixed composition in the open system.

$\mathrm{CaO}-\mathrm{SiO}_{2}-\mathrm{CO}_{2}-\mathrm{H}_{2} \mathrm{O}$. The univariant decarbonation reaction $\mathrm{CaCO}_{3}+$ $\mathrm{SiO}_{2} \rightleftharpoons \mathrm{CaSiO}_{3}+\mathrm{CO}_{2}$ was investigated experimentally by Harker and Tuttle (1956) using an excess of $\mathrm{CO}_{2}$. When $\mathrm{H}_{2} \mathrm{O}$ is present as well as $\mathrm{CO}_{2}$ the reaction can be represented within isobaric tetrahedra $\mathrm{CaO}-\mathrm{SiO}_{2}-$ $\mathrm{CO}_{2}-\mathrm{H}_{2} \mathrm{O}$ by movement of a four-phase tetrahedron calcite + quartz + wollastonite + vapour as the vapour phase changes composition towards $\mathrm{CO}_{2}$. The principles are the same as for the system $\mathrm{CaO}-\mathrm{MgO}-\mathrm{CO}_{2}-\mathrm{H}_{2} \mathrm{O}$.

Conclusion. These examples confirm that the effect of inert volatiles on complex decarbonation reactions is similar to their effect on the dissociation of magnesite. Inert volatiles have the same effect on any univariant dissociation reaction and in particular on dehydration reactions. For many dehydration reactions $\mathrm{CO}_{2}$ is a non-reacting and therefore inert component unless its concentration in the vapour phase is high. The effect of $\mathrm{CO}_{2}$ on the dissociation of brucite is illustrated in the $T X$ prism for the system $\mathrm{MgO}-\mathrm{CO}_{2}-\mathrm{H}_{2} \mathrm{O}$ (Walter, Wyllie, and Tuttle, 1962). In this example $\mathrm{CO}_{2}$ ceases to act as an inert component when its concentration in the vapour phase exceeds 6 weight per cent at 1000 bars pressure; brucite is then replaced by magnesite.

In summary, for both open and closed systems at constant total pressure the temperature of beginning of dissociation is lowered according to the proportion of inert volatiles present in the initial vapour phase. The dissociation proceeds to completion at one temperature in the open system whereas in the closed system it proceeds through a dissociation interval and most of the reaction is delayed until the temperature approaches the univariant curve for the dissociation when no inert components are present. For magnesite the reaction hardly begins until the temperature is within $10^{\circ} \mathrm{C}$ or $20^{\circ} \mathrm{C}$ of the dissociation temperature in the system $\mathrm{MgO}-\mathrm{CO}_{2}$. However, if the vapour phase in a closed system contains an inert volatile or volatiles the product of a dissociation reaction may be a stable phase, even if small in amount, at temperatures well below the dissociation temperature in the presence of a 'pure' vapour phase. 
The difference between open and closed systems as treated here is that the vapour-phase composition remains constant in the former, and it changes composition in the latter. A partially open system is conceivable in metamorphism where the vapour phase could change composition during a dissociation reaction although external conditions were tending to restore its original composition. If this should happen the pattern of dissociation would be similar to that for a closed system.

\section{Metamorphic reactions.}

The simple and consistent relationships in mineral parageneses suggest that there is a close approach to equilibrium in metamorphic reactions, but there are many examples that appear to represent disequilibrium because they contain more minerals than are required by the mineralogical phase rule (even excluding minerals of relict or retrogressive origin). Such mineral assemblages may represent disequilibrium or they may represent equilibrium in a system with a large number of independent components. Bowen (1925) stressed the 'fundamental assumptions as to the number of components' required to represent a metamorphic system with particular reference to $\mathrm{MgO}$ and FeO. The data analysed in this paper indicate that under some conditions pore-fluid components that do not enter into a reaction at all may have to be treated as one additional component for application of the mineralogical phase rule.

Progressive metamorphism results in a series of dehydration and decarbonation reactions and others involving no release of volatile components. These reactions are represented on Bowen's (1940) petrogenetic grid by univariant $P T$ curves giving the upper limits for the stability of specific minerals or mineral assemblages. Most experimental studies have been aimed at the location of such curves. Metamorphic reactions probably occur in the presence of a pore fluid (which must be very small in amount) containing $\mathrm{H}_{2} \mathrm{O}, \mathrm{CO}_{2}$, and other components, and the pore-fluid pressure may be less than the pressure on the rock; moreover, the pore fluid may be able to move into or out of a rock. These variable factors could lead to considerable changes in the temperature of a metamorphic reaction compared to its position on the petrogenetic grid, and fig. 3 illustrates some of the changes that could occur in response to metamorphic conditions.

Three of the major variables in metamorphism are $P, T$, and variation of the pore-fluid composition between $\mathrm{H}_{2} \mathrm{O}$ and $\mathrm{CO}_{2}$. Their effects on 
metamorphic reactions can be illustrated graphically in a three-dimensional model with mutually perpendicular axes representing the variables. This extension of Bowen's concept of a grid may be called a petrogenetic model. It can be constructed from experimental data for reactions occurring in the presence of $\mathrm{H}_{2} \mathrm{O}$ and $\mathrm{CO}_{2}$ (and inert volatiles). It may eventually be possible to evaluate the chemical potentials or activities of $\mathrm{H}_{2} \mathrm{O}$ and $\mathrm{CO}_{2}$ within the model and this would facilitate its use in tracing reactions occurring under either open or closed conditions. A more extended account must be reserved for a later publication.

Before pressures and temperatures attained during metamorphism can be estimated by comparing natural mineral assemblages with experimentally determined reaction curves we must be reasonably certain what processes are involved in the formation of minerals. In fact, the wide range of opinions concerning such factors as pore-fluid composition, mobility, pressure, and function during metamorphism could lead to very different estimates of metamorphic temperatures. Comparison of the pattern of reactions occurring under known experimental conditions may provide information about metamorphic processes. For example, if a metamorphic dissociation reaction is heralded by signs of incipient reaction in rocks of lower grade than those characterized by this reaction, the presence of an 'impure' pore fluid that changed composition during the reaction may then be implied, with the inference that conditions were either closed or only partially open.

Acknowledgements. G. A. Chinner, T. N. Clifford, H. I. Drever, R. Johnston, and W. S. MacKenzie very kindly reviewed drafts of the manuscript or helped by discussing problems. The paper developed from experimental studies in the systems $\mathrm{CaO}-\mathrm{MgO}-\mathrm{CO}_{2}-\mathrm{H}_{2} \mathrm{O}$ and $\mathrm{CaO}-\mathrm{SiO}_{2}-\mathrm{CO}_{2}-\mathrm{H}_{2} \mathrm{O}$ pursued at The Pennsylvania State University and at Leeds University (School of Chemistry). These studies were supported by the National Science Foundation (U.S.A.) and the Department of Scientific and Industrial Research (U.K.).

\section{References.}

Bowen (N. L.), 1925. Journ. Washington Acad. Sci., vol. 15, p. 280.

1940. Journ. Geol., Chicago, vol. 48, p. 225.

GraF (D. L.) and Goldsmith (J. R.), 1955. Geochimica Acta, vol. 7, p. 109.

Greenwood (H. J.), 1960. Bull. Geol. Soc. Amer., vol. 71, p. 1874 (abstr.).

HARKeR (R. I.), 1958. Amer. Journ. Sci., vol. 256, p. 128.

- and Tutrle (O. F.), 1955. Amer. Journ. Sci., vol. 253, p. 209.

1956. Amer. Journ. Sci., vol. 254, p. 239.

Коржинсгий (Д. С.) [Ковzhrnsктй (D. S.)], 1936. [Иәв. Акад- Наук СССР, Cep. Геол. (Bull. Acad. Sci. URSS, sér. géol.), vol. 1, p. 35]; quoted by Korzhinskiī, 1959.

1959. Physicochemical basis of the analysis of the paragenesis of minerals. Consultants Bureau, Inc., New York.

Sмyтн (F. H.) and Adams (L. H.), 1923. Journ. Amer. Chem. Soc., vol. 45, p. 1167. 
Thompson (J. B.), 1955. Amer. Journ. Sci., vol. 253, p. 65.

Walter (L. S.), Wyllie (P. J.), and Tuttle (O. F.), 1962. Journ. Petrology, in press.

Wyllie (P. J.) and Tuttle (O. F.), 1959. Amer. Journ. Sci., vol. 257, p. 648. 1960. Journ. Petrology, vol. 1, p. 1.

- - 1961. Amer. Journ. Sci., vol. 259, p. 128.

Yoder (H. S.), 1954. Carnegie Inst. Washington Year Book 53, p. 121. 